\title{
Moustapha Guèye, Le Tourisme en Casamance. Entre pessimisme et optimisme
}

coll. Harmattan Sénégal, Harmattan, 2010, 67 pages

\section{Benjamin Taunay}

\section{OpenEdition}

\section{Journals}

Édition électronique

URL : http://journals.openedition.org/tourisme/528

DOI : 10.4000/tourisme.528

ISSN : 2492-7503

\section{Éditeur}

Éditions touristiques européennes

\section{Édition imprimée}

Date de publication : 1 juin 2011

Pagination : 94-95

ISSN : 2109-5671

\section{Référence électronique}

Benjamin Taunay, "Moustapha Guèye, Le Tourisme en Casamance. Entre pessimisme et optimisme », Mondes du Tourisme [En ligne], 3 | 2011, mis en ligne le 30 septembre 2015, consulté le 22 septembre 2020. URL : http://journals.openedition.org/tourisme/528 ; DOI : https://doi.org/10.4000/tourisme. 528

Ce document a été généré automatiquement le 22 septembre 2020

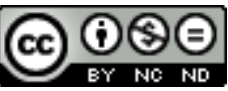

Mondes du tourisme est mis à disposition selon les termes de la licence Creative Commons Attribution - Pas d'Utilisation Commerciale - Pas de Modification 4.0 International. 


\title{
Moustapha Guèye, Le Tourisme en
}

\section{Casamance. Entre pessimisme et} optimisme

\author{
coll. Harmattan Sénégal, Harmattan, 2010, 67 pages
}

\section{Benjamin Taunay}

\section{RÉFÉRENCE}

Moustapha Guèye, Le Tourisme en Casamance. Entre pessimisme et optimisme, coll. Harmattan Sénégal, Harmattan, 2010.

1 Caricatural. Ce petit livre de 67 pages l'est en s'appropriant tous les stéréotypes qui continuent d'être associés au tourisme, sans avoir de recul critique, alors même que l'ouvrage se veut être une "étude" (p.13) sur le tourisme en Casamance et que l'auteur est titulaire d'un doctorat. Très intéressé par sa lecture, m'étant rendu dans la région il y a plusieurs années pour mes études, je dévorais pourtant d'avance ce livre. Que n'ai-je pu être déçu!

2 Avec ce livre, l'auteur souhaite "combler l'absence de travaux sur le secteur touristique durant ces dernières années en Casamance" (4 de couverture). Pour cela, Moustapha Guèye propose un plan en trois parties, digne d'un dossier de licence : 1 . Les grands atouts du tourisme en Casamance ; 2 . Le secteur touristique et la rébellion ; 3 . Le plan de relance des activités touristiques en Casamance. En clair et selon l'auteur, bien que la Casamance ait connu une longue rébellion indépendantiste (1982-2004), il est évident que le tourisme va très vite redémarrer, la région ayant des "atouts " (naturels: "le fleuve Casamance est un véritable paradis”, p. 20). Pour l'auteur, qui n'évite pas l'écueil déterministe (y a-t-il réfléchi ?), le tourisme n'est donc qu'une activité, fondée sur des "ressources" (p.17), des flux et des recettes. Un telle analyse, fondée sur des "tropismes" (comme la chasse par exemple, le tourisme "cynégétique", p. 16), est 
pourtant depuis longtemps caduque (Équipe Mit, 2002). Mais cela, l'auteur semble ne pas le savoir (il n'apporte qu'une très maigre bibliographie), considérant probablement (comme tant d'autres avant lui) que le tourisme est un sujet facile (futile ?) que tout un chacun peut traiter...

3 Avec beaucoup de zèle et d'ambition ${ }^{1}$, l'auteur veut montrer que le tourisme est forcément un outil pour un nouveau développement économique de la région ("le tourisme représente d'énormes potentialités pour la région", p. 40). Il donne alors une argumentation très personnelle autour de son idée force (même si aucune problématique n'est avancée): le pessimisme n'est pas de mise en Casamance, les "atouts" et l'investissement de l'État sénégalais vont balayer la rébellion et redonner de l'"optimisme" à la région. On est ici loin d'un discours neutre, comme doit l'être celui d'un scientifique. C'est un acteur du développement qui parle, qui n'hésite pas à fustiger les indépendantistes casamançais - qui ont mis le "désordre" (p. 27), et dont le chef historique a toujours eu un discours "arrogant", "guerrier", "incendiaire" (p. 31) -, voire les populations locales - "qui faisaient une interprétation fallacieuse de la réalité" (p. 26). Même des connotations politiques sont présentes, l'auteur proposant de longues citations du président sénégalais (pp.35-36) et admirant sa "brillante victoire" (électorale, p. 30). Le lecteur sera enfin souvent surpris par quelques formulations : "les principales ressources sont constituées par [...] les cérémonies traditionnelles (funérailles, circoncisions)" (pp. 17-18)...

4 L'auteur le reconnaît lui-même : "malgré tous ses atouts, la Casamance n'arrive toujours pas à diversifier son tourisme" (p. 47). C'est peut être à partir de ce constat qu'il aurait fallu commencer l'“étude"? De plus, la thématique "tourisme et développement", certes intéressante, n'est-elle pas à dépasser? Le lien entre sortie de crise (militaire) et tourisme est absent de ce livre, alors qu'il mériterait des développements. Plus pertinente encore, la thématique du tourisme intérieur (domestic tourism, en anglais), abordée (pp. 21-22), mais pas développée au-delà des objectifs fixés par le gouvernement, serait à approfondir : le continent noir reste à la marge du tourisme mondial et rares sont ceux qui se sont penchés sur les tourismes intérieurs qui y naissent. Qu'en est-il au Sénégal, un des pays qui tirent économiquement le développement de l'Afrique de l'Ouest?

Bref, on ne retiendra de ce livre que la synthèse sur l'histoire de la rébellion indépendantiste casamançaise, rappel très utile et fort bien retracé. Pour le reste, le lecteur soucieux d'un travail de qualité sur la question posée (si question il y a) passera son chemin. Être docteur de l'université Paris 1 n'est pas (forcément) un gage de qualité et n'est pas spécialiste du tourisme qui le décide. Le livre n'en demeure pas moins un modèle; mais de ce qu'il ne faut pas faire. Dans une certaine mesure, on comprend, parfois, que l'Aeres prenne de moins en moins en compte les ouvrages dans ses analyses bibliométriques. 


\section{NOTES}

1. Moustapha Guèye est le chef du département d'économie et de gestion de l'université de Ziguinchor (chef-lieu de la Basse Casamance). 